\title{
A PONTUAÇÃO COMO RECURSO DE ESTILO NO MINICONTO “FOSSO DO SOM", DE JoÃo GILBERTO NOLL
}

LEANDRO PASSOS*

\section{Resumo:}

Este artigo propõe-se a analisar e descrever o modo como a pontuação normativa da Língua Portuguesa desconfigura-se no miniconto "Fosso do som", de João Gilberto Noll, de sua obra Mínimos, Múltiplos, Comuns e, por isso, funciona como recurso de estilo que contribui para a estruturação da trama poética da narrativa. Além disso, tendo em vista o desvio desta regra gramatical em questão, será observada a estrutura sintática do texto que resulta em elipses frasais e da própria estrutura do gênero prosa conforme os formalistas russos.

PALAVRAS-CHAVE: miniconto, trama, pontuação, elipse, função poética.

\section{INTRODUÇão}

O miniconto "Fosso do som", composto por apenas 94 palavras, está inserido em "Gênese", na parte "O verbo", da seção "Palavras":

Ele caminhava pelo campo. Na iminência da explosão de uma palavra. Que ele não queria que se desse entre aquela relva alta, ruiva de calor. Precisava chegar à tapera. Ali daria enfim passagem à coisa que lhe forçava a mandíbula, tentando ser pronunciada de uma vez. Ao entrar, percebeu que a voz não era a dele. Uma percussão, quem sabe, com o seu oco ainda em formação. Procurando o cavo, o mais grave pendor. Deitou na esteira. Ouviu o violino do irmão, na mata, atraindo certa lembrança impossível, aquela, afogada no fosso do som... (NOLL, 2003, p. 39).

* Professor de Língua Portuguesa do Instituto Federal de Educação, Ciência e Tecnologia de Mato Grosso do Sul (IFMS), Três Lagoas, Mato Grosso do Sul, Brasil. E-mail: lelopassos@, gmail.com 
O miniconto "Fosso do som" permite-nos descrever e perceber a fábula, o que não quer dizer, aliás, que a trama não seja significativa. Fábula e trama são vistas, nestas considerações, como "conjunto de acontecimentos ligados entre si que nos são comunicados no decorrer da obra" (TOMACHEVSKI, 1976, p. 173), e ao modo como esses acontecimentos estão sequenciados, fornecendo, ao leitor, o conhecimento do que se passou, ou seja, a maneira como os fatos são organizados.

Trata-se da história de uma personagem que caminha pelo campo para chegar a uma tapera, pois não quer que a "explosão da palavra" ocorra na relva. Ao chegar ao local almejado, ela sente que a voz que sai não é a dela, por isso, deita na esteira e ouve o violino do irmão.

Mesmo que a identificação da fábula nos seja um pouco mais tranquila, a linguagem oblíqua e singular está presente. Quando ressaltamos a questão da linguagem aqui, queremos deixar claro que a sugestão, a conotação e a imagem poética destacam-se no desenvolvimento da narrativa. Logo, ocorre uma ilusão de entendimento, pois a fábula está mascarada e obliterada por uma linguagem que se faz "cínica". Assim, o leitor precisa estar atento às armadilhas da trama narrativa.

Um fator interessante, nesse sentido, é a pontuação dos enunciados. A sintaxe do miniconto é cortada pelo ponto final, cuja função, consoante Cunha e Cintra (2001, p. 650), é indicar o término de uma oração declarativa. Porém, salientam os mesmos autores, "o ponto tem sido utilizado pelos escritores modernos onde os antigos poriam ponto-e-vírgula ou mesmo vírgula. Trata-se de um eficiente recurso estilístico, quando usado adequada e sobriamente" (CUNHA; CINTRA, 2001, p. 651).

Um dos efeitos provocados por esse recurso explicado por Cunha e Cintra (2001), presente em "Fosso do som", seria a da contenção da personagem que não quer a explosão da palavra na "relva alta, ruiva de calor". Segmentado o período, a linguagem iconiza a tentativa de conter a "palavra", e a fluidez da leitura é "barrada" pelo ponto; é como se o ponto bloqueasse a passagem de ar na produção do som, o que transformaria o sinal de pontuação em signo poético. 
O vocábulo "fosso", presente no título do miniconto, pode ser: 1. Cova; 2. Valeta que se abre ao longo das estradas para receber as águas das chuvas; e 3. Vala profunda que rodeia acampamentos, fortificações etc.; (AULETE, 2011, p. 421). É possível associar esses significados de fosso à "traqueia", tubo aéreo que se inicia na parte inferior da laringe, terminando onde se dá sua bifurcação; daí para frente iniciam-se os brônquios. Desse modo, os sons da língua são produzidos quando o ar sai dos pulmões e percorre a traqueia (fosso) e a laringe. Órgão que faz parte do sistema respiratório e do aparelho fonador, do processo de produção dos sons, a traqueia tornou-se elemento motivador da forma de conteúdo e do conteúdo do miniconto, pois a personagem retém a "explosão de uma palavra".

Silva (2003, p. 24), ao glosar o aparelho fonador, observa que as partes do corpo humano que utilizamos na produção da fala têm como função primária atividades como mastigar, engolir, respirar ou cheirar. A autora destaca que não existe nenhuma parte do corpo humano cuja função única esteja somente relacionada à fala; portanto, os órgãos utilizados na produção da fala não têm como função primeira a articulação dos sons. Cabe, ao aparelho fonador, a produção de qualquer som de qualquer língua, destaca Silva (2003).

O aparelho fonador, assim, é dividido em três sistemas: respiratório, fonatório e articulatório. Interessa-nos, por ora, o primeiro deles, formado pelos pulmões, pelos músculos, pelos brônquios e pela traqueia (fosso do som). A função primária deste sistema é, evidentemente, a produção da respiração. Por participar do aparelho fonador, a traqueia teria, então, como função elementar, a respiração, e, secundariamente, a fonação.

Essa "escolha" do minicontista na estruturação da narrativa pode ser relacionada à própria palavra, ao próprio signo verbal, que serve tanto à prosa como à poesia. A traqueia é respiração ao mesmo tempo em que é fonação; torna-se signo poetizado por essa narrativa concisa, tramada por uma linguagem oblíqua e opaca.

Miniconto ícone, que quer se "comportar" como a "luta" da personagem em conter a "explosão" da palavra, ou melhor, a exteriorização do som, "Fosso do som" opera por meio de recursos particulares da poesia. Além disso, é preciso levar em consideração, 
também, o recurso de pontuação, ponto final versus vírgula, ou ponto e vírgula, porque teríamos, assim, uma série de frases nominais e elipses de elementos sintáticos como em "Na iminência da explosão de uma palavra", "Que ele não queria que se desse entre aquela relva alta, ruiva de calor", "Uma percussão, quem sabe, com o seu oco ainda em formação" e "Procurando o cavo, o mais grave pendor" (NOLL, 2003, p. 39).

O primeiro enunciado do miniconto, "Ele caminhava pelo campo", pode ser considerado a "frase-base" da narrativa, já que os demais o seguirão como elementos de complemento. Não há, então, elipse desse fragmento. Além de "enunciado-base", podemos dizer que o fragmento é a forma verbal mínima, no sentido de Genette (197-), a ser desenvolvida na narrativa, isto é, a sua ampliação.

O segundo, "Na iminência da explosão de uma palavra", configurar-se-ia como um enunciado nominal, elíptico de outros elementos (sujeito e predicado), mas pode ser completado pelo enunciado anterior, se levarmos em conta a normatividade da pontuação. Neste momento, começamos a ter a informação de que a personagem quer reter a articulação da palavra, a sua explosão. Ora, o miniconto flagra o instante mais singular e significativo de um continuum; a personagem está "prestes a" articular a palavra, a produzir o som, ou, de acordo com o texto, "na iminência da". Estar na "iminência de" é o clique narrativo do miniconto que se utiliza da linguagem poética para relatar o fato.

Em "Que ele não queria que se desse entre aquela relva alta, ruiva de calor", terceiro enunciado, também percebemos o recorte do enunciado operado pelo ponto final no lugar da vírgula. Trata-se, o fragmento, de uma oração subordinada adjetiva que qualifica, por conta de sua estrutura sintática, "a palavra", que, no eixo sintagmático, está no enunciado anterior.

Se o miniconto (o todo) iconiza a tentativa da personagem em reter a explosão da palavra, o terceiro enunciado (a parte) potencializa essa relação entre as formas e os planos de conteúdo, tendo em vista que há uma "ilusão" de equilíbrio entre as consoantes surdas (9) e as sonoras (13). Lemos, "Que ele não queria que se desse entre aquela relva alta, ruiva de calor", no qual as consoantes $/ \mathrm{k} /, / \mathrm{s} /, / \mathrm{t} /$ são surdas; e as sonoras $/ 1 /, / \mathrm{n} /, / \mathrm{r} /, / \mathrm{d} /, / \mathrm{v} /$. 
Sobre as surdas (som desvozeado) e as sonoras (som vozeado), Silva (2003, p. 27) explica que estas se realizam quando as cordas vocais vibram durante a produção de determinado som, e aquelas quando não houver vibração. O som vozeado, portanto, ocorre porque os músculos que formam a glote aproximam-se e, devido à passagem da corrente de ar e da ação dos músculos, ocorre a vibração. No desvozeado, por outro lado, não há vibração das cordas vocais, tampouco ruído durante a produção, pois os músculos que formam a glote encontram-se completamente separados de modo que o ar passa livremente.

No fragmento em questão, há maior produção de som vozeado (13), contudo, a de som desvozeado (9) não é tão inferior assim; estrutura que podemos relacionar à luta, ao embate da personagem para "conter" a explosão do som. Outros aspectos que salientam essa contenção são os ápices e as quedas da tonicidade da expressão "relva alta, ruiva de calor", nas quais temos: relva, alta, ruiva, de, calor. Essa subida e descida da tonicidade iconiza e imita a aflição da personagem ao reter a explosão da palavra. Há, como dissemos, subida seguida de descida em "rel $\boldsymbol{\Delta}$ va $\boldsymbol{\nabla}$ ", "al $\boldsymbol{\Delta}$ ta $\boldsymbol{\nabla}$, "ru $\boldsymbol{\Delta}$ iva $\boldsymbol{\nabla}$ "; " $\boldsymbol{\nabla}$ de ca $\boldsymbol{\nabla}$ lor $\boldsymbol{\Delta}$ ".

Ainda, no que diz respeito ao som das palavras, verificamos a "disputa na retenção" da palavra da seguinte forma: relva, com a primeira consoante da sílaba fricativa velar desvozeada, a segunda lateral alveolar vozeada velarizada, e a da segunda sílaba fricativa labiodental vozeada (desvozeada - vozeada versus vozeada); alta, com a primeira consoante da sílaba lateral alveolar vozeada velarizada, e a da segunda sílaba oclusiva alveolar desvozeada (vozeada versus desvozeada); ruiva, com a primeira consoante da sílaba fricativa velar desvozeada, e a da segunda fricativa labiodental vozeada (desvozeada versus vozeada); de, monossílaba, oclusiva alveolar vozeada; e calor, com a primeira sílaba oclusiva velar desvozeada, e a segunda lateral alveolar vozeada (vozeada - desvozeada versus vozeada).

É necessário lembrar que uma sílaba acentuada é produzida com certo impulso torácico reforçado; "temos um jato de ar mais forte (em relação às sílabas não acentuadas ou átonas)" (SILVA, 2003, p. 77). Além disso, a tonicidade é percebida como tendo mais duração, sendo pronunciada de maneira mais alta. A personagem de "Fosso do som", na iminência da explosão, "trava" uma luta interna a fim de que a palavra fique em seu interior. 
Cabe, nesse momento, observar a questão do espaço da narrativa, aberto (campo) e fechado (tapera), que contribui para a singularização da fábula e da trama do miniconto. Carlos Augusto de Figueiredo Monteiro, no texto O mapa e a trama - Ensaios sobre o conteúdo (2002), embora tenha enfatizado que seu trabalho não se refere a uma crítica literária dos textos, procurou, em suas análises, estabelecer uma mediação entre o real e o texto literário, ou seja, entre Geografia e Literatura. Diz o autor:

Entendo que a importância conferida à trama liga-se ao fato de que ela é aquilo que, em seu dinamismo, representa a "condição humana". A sua comunicação, o seu "tomar vida", requer, forçosamente, a projeção dessa trama num dado espaço-tempo, um "palco" - praticável, concreto - em que qualquer trama "humana" está envolta nas malhas de diferentes espaços relacionais: social, político, econômico, cultural enfim. (MONTEIRO, 2002. p. 24-25).

Trazemos, primeiramente, esses apontamentos de Monteiro (2002) por entrar em consonância com a "condição" ou drama da personagem. Ainda que de modo paradoxal, o espaço aberto e o fechado figurativizam a "explosão do som", assim como a glote e as cordas vocais na produção dos sons vozeados e desvozeados. Há, desse modo, além da "representação da condição" da personagem, a construção de um palco ambíguo que, de certo modo, influencia o ser e o estar da protagonista do miniconto. O espaço aberto serviria de motivação para a liberação do som, e o aberto, por sua vez, motivaria o fechamento da glote e das cordas vocais.

Osman Lins, em Lima Barreto e o espaço romanesco (1976), reflete sobre questões do espaço, apresentando a heterogeneidade do seu uso: a possibilidade do espaço como uma referência bastante ampla a depender da particularidade da fábula e da trama da narrativa. O espaço é capaz, a depender da poética de cada escritor, de suscitar e singularizar as lutas que se travam pela sobrevivência, os espaços imaginário, físico, fantástico, social, mítico, sobrenatural, etc.

O próprio Lins (1976) destaca que uma tipologia rígida na categorização do espaço narrativo seria incompleta e ineficaz, e observa que a classificação constitui uma ilustração das suas possibilidades; o 
autor reforça, simultaneamente, a importância que pode ter na ficção esse elemento estrutural e indica "as proporções que eventualmente alcança o fator espacial numa determinada narrativa, chegando a ser, em alguns casos, o móvel, o fulcro, a fonte de ação [...]" (LINS, 1976, p. 67).

O contraste entre conter a palavra no espaço aberto (campo) e liberá-la no espaço fechado (tapera) torna-se fulcral na caracterização da tensão narrativa, uma vez que a abertura do espaço provocaria ou motivaria a abertura do aparelho fonador, o que acabaria frustrando a personagem.

Ozíris Borges Filho, em Espaço e literatura: introdução à topoanálise (2007), partindo dos conceitos de Gaston Bachelard (1989), de sua obra $A$ poética do espaço, também chama a atenção para o fato de que a criação do espaço dentro do texto literário serve a variados propósitos e seria tarefa ingrata e fracassada separar e classificar todos eles. Mesmo assim, o autor elenca algumas classificações, dentre as quais, as que nos interessam, são:

1.5 Representar os sentimentos vividos pelas personagens. Esses não são espaços em que a personagem vive, mas são espaços transitórios, muitas vezes, casuais. Assim, em determinadas cenas, observamos que existe uma analogia entre o espaço que a personagem ocupa e o seu sentimento. Por exemplo, teremos uma cena de alegria que se passa sob o sol fresco de um fim de tarde, brilhante, num céu com poucas nuvens e passarinhos voando. Parece que, como a personagem, a natureza está alegre, portanto há uma relação de homologia entre personagem e espaço. Trata-se de um espaço homólogo.

1.6 Estabelecer contraste com as personagens. Nesse caso, ocorre o oposto do mencionado anteriormente. Isto é, não há nenhuma relação entre sentimento da personagem e espaço. $\mathrm{O}$ espaço mostrasse indiferente, estabelece uma relação de contraste. Por exemplo, suponhamos que o protagonista tenha perdido sua mãe, devido a uma terrível infecção. No momento do enterro, temos o seguinte espaço: sol, céu azul, poucas nuvens, vento fresco, passarinhos cantando alegremente. Nesse caso, o espaço estabelece um contraste com o íntimo da personagem, há, portanto, uma relação de heterologia. Trata-se de um espaço heterólogo. 
1.7 Antecipar a narrativa. Através de índices impregnados no espaço, o leitor atento percebe os caminhos seguintes da narrativa. Em outras palavras, há uma prolepse espacial. Por exemplo, suponhamos que o herói está se escondendo de seu algoz. O narrador, ao apresentar o espaço em que o herói se encontra, mostra-nos uma faca em cima de uma mesa. Momentos depois, é justamente aquela faca que servirá para a defesa do herói. Com isso, destaca o autor, é preciso associar o elemento narrativo espaço com os demais constituintes da narrativa. (BORGES FILHO, 2007, p. 3).

Borges Filho (2007) diz que a "arquitetura" do espaço na obra literária é igualmente importante para as ações da personagem e desempenha inúmeras funções dentro da narrativa. Em "Fosso do som", o que denominamos de relação paradoxal é justamente a ausência da "homologia" entre a personagem e o espaço; a relação espacial ligase mais ao contraste (aberto e fechado). Contudo, o espaço aberto do campo perde o seu valor de índice, já que a personagem consegue chegar à tapera e exteriorizar o som; a antecipação sugerida pelos espaços não se configura.

No quarto enunciado, o narrador relata a necessidade de a personagem chegar à tapera; a caminhada da personagem do campo à tapera corresponde ao andar da narrativa, o seu prosseguimento. Esse fragmento do conto não apresenta elipses que funcionam como recurso estilístico porque o leitor consegue, facilmente, identificar o sujeito oculto "ele" do verbo "precisar".

O quinto, embora não apresente elipse, frase nominal, tampouco reticências, inicia-se com o elemento adverbial de espaço "Ali", dêitico que remete à tapera e produz a noção de encadeamento presente no miniconto. Gonçalves (s.d., p. 116) explica que esse recurso é uma figura de pensamento que "consiste na omissão intencional de algo que deveria ou que se poderia dizer e que, por motivos próprios do enunciador, não é dito". Há, então, um plano de conteúdo ausente marcado por esse recurso gráfico que, por não estar escrito por meio da linguagem verbal, se faz presente, apenas, por meio do sinal que o representa: (...). Então, as reticências são recursos gráficos que sugerem a omissão daquilo que se devia ou podia dizer; o silêncio voluntário; "indica" suspensão do sentido ou omissão de palavras. 
O clima de tensão, nesse fragmento, ainda é latente porque não sabemos se, de fato, a explosão vai ocorrer na relva; a expressão "coisa que forçava a mandíbula" potencializa a atmosfera de estranhamento da narrativa e nos faz pensar se se trata de uma palavra que quer se exteriorizar "de uma vez".

Essa dúvida lembra-nos a tese do conto conforme Piglia (2004), ao discutir o caráter duplo dessa forma narrativa. $\mathrm{O}$ autor toma por base as notas dos cadernos de Tchekhov, nas quais havia a seguinte anedota: Um homem em Montecarlo vai ao cassino, ganha um milhão, volta para casa, suicida-se. Conforme Piglia, "a forma clássica do conto está condensada no núcleo desse relato fictício e não escrito" (PIGLIA, 2004 , p. 89). No conto, a intriga se oferece como um paradoxo, o que resulta no caráter duplo desse tipo de narrativa: "um conto sempre conta duas histórias". Com isso, o conto narra, em primeiro plano, a história 1, que seria o relato do jogo de Tchekhov, e arquiteta, em segredo, a história 2, no caso, o relato do suicídio. "A arte do contista baseia-se em saber cifrar a história 2 nos interstícios da história 1", comenta Piglia (2004, p. 89-90).

Para o ensaísta, um relato visível esconde um relato secreto, narrado de modo elíptico e fragmentário. Desse modo, a surpresa é uma consequência da imersão do final da história secreta na superfície. Portanto, as duas histórias são contadas de modo distinto, pois "trabalhar com duas histórias, quer dizer trabalhar com dois sistemas diferentes de causalidade. Os mesmos acontecimentos entram simultaneamente em duas lógicas narrativas antagônicas" (PIGLIA, 2004, p. 90). Com isso, os constituintes indispensáveis de um relato têm dupla função e são selecionados e combinados de maneira diferente em cada uma das duas histórias: "Os pontos de interseção são o fundamento da construção" (PIGLIA, 2004, p. 90).

É importante destacar ainda, das observações de Piglia (2004), que o supérfluo numa história é básico na outra. O conto é formado e estruturado por uma matéria ambígua que põe em funcionamento a sua microscópica máquina narrativa (PIGLIA, 2004, p. 91).

No relato 1 , teríamos o relato da personagem que precisa chegar a uma tapera para dar passagem à palavra que lhe força a mandíbula. $\mathrm{O}$ relato 2, narrado em segredo e imbricado ao relato 1 , gira em torno do 
próprio estranhamento da fábula e que nos faz pensar em que medida trata-se, apenas, da contenção de uma palavra, do que foi pronunciado e que o fez perceber que não se trata de sua própria voz, verificada no sexto enunciado. O estranhamento, então, realiza-se tanto na forma de conteúdo como no próprio conteúdo.

O sétimo enunciado, assim como o título do miniconto, possui elementos que estão no campo semântico dos elementos sonoros (som, percussão, oco) e dos elementos da seção em que o texto está presente, "Gênese": em formação. Percussão pode tanto estar relacionada ao "choque", ao embate entre dois corpos, quanto à prática médica que consiste em dar pequenas pancadas com os dedos sobre as paredes das cavidades do corpo a fim de reconhecer, pelo som produzido, prováveis lesões contidas no interior dessa cavidade, portanto, significados que nos remetem aos próprios instrumentos de percussão, cujo som é resultante de uma batida em uma superfície elástica.

Assim, o ponto final no lugar da vírgula pode ser relacionado ao toque ou à batida na linha sintagmática do miniconto, além de impedir a explosão da palavra. Nesse trecho, o enunciado pode ser a caracterização da "voz que não era a dele", presente no fragmento anterior e, ao mesmo tempo, constituir-se de uma frase nominal.

O estranhamento causado pela não identificação da própria voz, juntamente com a ambiguidade proporcionada pelo eixo sintagmático do oitavo enunciado, por conta da incerteza de atribuição da predicação verbal "procurando", homologa-se ao sentido do fragmento do miniconto. Algo procura o "cavo, o mais grave pendor"; expressões que dão a ideia de cavidade e fenda como também remetem aos aspectos sonoros presentes no texto.

A ambiguidade e a incerteza configuram-se como "lacunas", como "fendas" que nos dão, como dissemos anteriormente, a "ilusão de tranquilidade" na fábula e faz perceber a singularização da trama.

É interessante destacar a expressão "grave pendor" que, por conta de seus conteúdos semânticos, rígido, circunspecto, penoso ou mesmo nota musical baixa, sugere a não resolução plena do conflito da personagem. Ocorre, ainda, a propensão para permanência desse estado de angústia: reter a explosão da palavra, exteriorizá-la e não reconhecêla, posteriormente. 
Essa atmosfera de tensão é quebrada pelo evento que se segue, "Deitou na esteira". Há uma quebra de expectativa, e o leitor espera a resolução desse conflito que, inesperadamente, muda de tom. Essa mudança de tom desestrutura o que até então era narrado, porque, justamente, equilibra o que estava desequilibrado: a personagem deita $\mathrm{e}$ ouve o violino do irmão na mata.

A personagem, no espaço fechado interior da tapera, ouve o instrumento musical violino do irmão no espaço aberto (mata); assim, o som de percussão que perpassa toda a narrativa desde as linhas iniciais, nas linhas finais, muda para o instrumento de corda. Logo, não há mais batidas, mas, sim, a vibração das cordas. A quebra de expectativa, então, parece entrar em consonância com o pequeno volume que a vibração da corda do instrumento produz, se comparada à batida ou ao toque dos instrumentos de percussão.

Enfim, levando em consideração as estruturas da narrativa, teremos elipse da situação inicial, presente em toda narrativa (TODOROV, 1986), pois uma força já perturbou a situação estável da personagem; o miniconto inicia-se já com o estado de desequilíbrio instaurado, o que é peculiar a essa forma narrativa concisa.

A força dirigida em sentido inverso pode ser verificada no texto como o esforço da personagem em conter a explosão da palavra no espaço aberto relva alta, êxito obtido porque a exteriorização da voz ocorre no espaço fechado "tapera". Contudo, a restauração do equilíbrio da narrativa é ambígua e estranha, pois a personagem tem a impressão de que a voz que sai não é a dela, e por conta da quebra de expectativa da narrativa na mudança de tom. Todorov (1986) observa que o segundo equilíbrio nunca é idêntico ao primeiro, o que em "Fosso do som" incita o leitor a pensar como seria, de fato, a situação inicial da narrativa, que está fora da moldura.

Aliás, o miniconto, por potencializar a estrutura concisa do conto, oferece-nos lacunas, ou melhor, um oco, um cavo, um fosso na plenitude dos elementos narrativos, tal como a presença desse irmão que toca violino. Apenas nas linhas finais do texto é que tomamos conhecimento de que a protagonista possui um irmão, fragmento finalizado pela reticência. 
Conforme Jung (1984 [1945]), por exemplo, embora exista certa Exposição em que é indicada a ação dos fatos e das personagens, não há a indicação e descrição dos pormenores da situação inicial. $\mathrm{O}$ Desenvolvimento está instaurado desde as primeiras linhas, a situação inicial já está complicada e a tensão estabelecida; a Peripécia, por sua vez, se realiza, pois a narrativa muda de tom: a personagem consegue chegar à tapera e deixar a palavra "explodir" e, além disso, a situação muda completamente. A Lise, Solução ou Resultado também estão presentes na estrutura do miniconto por conta da resolução do problema que aflige a personagem.

Por outro lado, por conta da mudança de tom, o desfecho traz à tona o relato 2, narrado em segredo, e nos faz pensar em Piglia (2004) ao dizer que "os finais são formas de encontrar sentido na experiência. Sem finitude não há verdade [...]" (PIGLIA, 2004, p. 100). Ora, "Fosso do som" apresenta-nos as principais estruturas e elementos da narrativa, mas não perde a particularidade poética típica de minicontos contemporâneos.

Deste modo, apenas com o olhar voltado ao procedimento, aos recursos operatórios literários é que percebemos a "experiência" da linguagem. Por fim, em "Fosso do som", há narrativa, tendo em vista o tênue desenvolvimento da forma verbal mínima, com procedimentos singulares, para lembrarmos Chklovski, que resultam na função poética da linguagem no sentido proposto por Jakobson (1969).

O poético descrito neste trabalho por meio da análise do miniconto "Fosso do som" é visto como aquele procedimento linguístico que caracteriza toda obra poética e destaca o que lhe é indispensável e inerente: projeção do princípio de equivalência do eixo de seleção sobre o eixo de combinação, no qual, a seleção e as escolhas, são feitas em base de equivalência, semelhança e dessemelhança, sinonímia e antonímia, e trabalha com elementos ausentes e potenciais; a combinação e a construção das sequências baseiam-se na contiguidade. São, pois, diversas as possibilidades de projeção do princípio de equivalência do eixo de seleção sobre o eixo de combinação: quanto maior a escolha e a seleção, maior será a produção de sentidos e, consequentemente, a instauração da ambiguidade.

Tanto a escolha das palavras (eixo paradigmático) como o modo como são ordenadas (eixo sintagmático) no miniconto ressaltam uma 
linguagem que se faz oblíqua e motivada. Para Coronado (1969-1970, p. 41), na linguagem oblíqua, o significado radical e real se dilata e alarga-se por meio do contágio imaginário de outros significados dos mais variados modos. Através dessa relação, os sentidos tornam-se oscilantes e fluidos, dinamizando, assim, a realidade. A linguagem reta, por exemplo, apresenta um caráter redutivo, ao passo que a oblíqua constitui-se por uma linguagem alusiva aberta a outros horizontes, enriquecendo-se e se sensibilizando no que diz respeito ao trato da palavra literária.

Se pensarmos no trato do significante da linguagem oblíqua, sua opacidade resulta de que o escritor, em nosso caso o minicontista,

[...] aproveitando o sistema estabelecido e mantendo-o nas suas bases [...] introduz nos sinais comuns de comunicação algumas modificações pessoais que dão outra dimensão à mensagem linguística, embaçando inicialmente a superfície de sua transparência, o imediatismo da comunicação [...]. (CORONADO, 1969-1970, p. 41).

Ora, ao lermos "Fosso do som", não identificamos de imediato um relato propriamente dito, além disso, percebemos os fatos por meio dessa linguagem oblíqua e opaca que prefere menos situar e nomear a sugerir e instigar. A opacidade, ao contrário da transparência, faz uma curva no caminho da comunicação para motivar-se de significados mais ricos e ambíguos. Essa curva, aliás, completa Coronado (1969-1970, p. 41), realiza-se através de diversificados meios.

A linguagem do miniconto, assim, assume o recurso operatório oblíquo e opaco, oferecendo ao leitor "aberturas", que não precisam ser "fechadas" necessariamente, e exigem do leitor certa participação e atenção, pois, caso contrário, será "enganado" pelos recursos dessa narrativa imprecisa que frustra quaisquer tentativas de recuperação das estruturas tradicionais de relato, tais como introdução, desenvolvimento, conflito, resolução e desfecho.

Ainda conforme Coronado (1969-1970, p. 42-43), o esclarecimento de que a aplicação desses conceitos não é excludente: "sendo as obras literárias objetos culturais, resulta impossível, pela própria versatilidade e complexidade do produto cultural, construir um esquema classificatório baseado na exclusão mútua”. Logo, as 
linguagens reta e oblíqua coexistem em todo objeto artístico. Devemos, pois, apoiarmo-nos nesses conceitos para uma diferenciação e não pela exclusividade, o que resulta em certa predominância relevante de uma das formas.

De acordo com o autor, é pela predominância relevante que a linguagem reta ou a oblíqua constituem-se em formas linguísticas essenciais de determinado gênero literário e artístico. Portanto, por conta da escolha e da seleção dos elementos linguísticos para narrar acontecimentos, peculiaridade da prosa literária, o miniconto "Fosso do som" comporta-se como texto poético que mescla relatos e descrições, ações e reflexões, desenvolvimento e pausas.

Valéry (1999), ao refletir sobre a questão do fazer poético, fala da "limpeza" de situação verbal: "antes de qualquer exame sobre o conteúdo, olho para a linguagem; tenho o costume de agir como os médicos que purificam primeiro suas mãos e preparam seu campo operatório" (VALÉRY, 1999, p. 194). Conforme o autor, é importante que o poeta, desde o início, esteja consciente das possibilidades "oferecidas" e "impostas" pela linguagem. As "primeiras palavras" podem direcionar a obra para o universo poético ou para o lugar da linguagem cotidiana, pois é a linguagem a matéria da poesia, portanto, da literatura. Sendo a poesia a arte da linguagem, aponta Valéry, "certas combinações de palavras podem produzir uma emoção que outras não produzem, e que denominamos poética" (VALÉRY, 1999, p. 197).

A prosa, logo o miniconto, precisaria se valer do potencial desses recursos da linguagem a fim de se configurar como um objeto poético. "Fosso do som" entra nesse universo poético, descrito por Paul Valéry (1999), no qual a linguagem transforma-se em uma forma diferente da linguagem comum. A linguagem poética instaura-se por meio dessa "transformação", ou melhor, pela singularização da linguagem cotidiana que é sua matriz. Nesse universo, submetemo-nos a um novo regime, "sob leis que não são mais de ordem prática [...] nada do que se passar nesse estado estará resolvido, acabado, abolido por um ato bem determinado" (VALÉRY, 1999, p. 201). No miniconto, percebemos a estrutura narrativa, mas de maneira deslocada, diferente daquela à qual estamos acostumados. João Gilberto Noll (2003) destaca a matriz do esquema narrativo e o que lhe é mínimo; utiliza os resíduos do gênero 
num processo de seleção e combinação, que resulta na poética do miniconto.

A linguagem oferece uma gama de possibilidades, na qual cada vocábulo é uma montagem instantânea de um som e de um sentido, sem qualquer relação entre eles; cada frase é um ato sobremaneira complexo, resultando na diversidade e na confusão dos seus usos. $\mathrm{O}$ artista, portanto, "briga" com esta "matéria verbal", desafia o som e o sentido, desfamiliariza as regras convencionais, e é provocado pelas condições intelectuais e estéticas variadas.

Barthes (1970, p. 19) diz que "todo escrito se torna obra quando pode variar, em certas condições, uma primeira mensagem. [...] Essas condições de variações são o ser da literatura." É com a primeira linguagem, o "nomeado demais, que a literatura deixa debater-se: a matéria-prima da literatura não é o inominável, mas pelo contrário o nomeado; aquele que quiser escrever deve saber que começa uma longa concubinagem com uma linguagem que é sempre anterior" (BARTHES, 1970, p. 22).

Em "Fosso do som", a estrutura narrativa, ou melhor, o que se configura como a "reminiscência do gênero", problematiza o simples narrar de um fato, a sequência cronológica ou não do relato de um acontecimento. Verificamos novas possibilidades de narrar, nas quais, muitas vezes, a ação é posta em segunda ordem e o "estado lírico" de quem relata, o narrador, é ressaltado. A estrutura prática da prosa revelase a partir de uma leitura intervalar, portanto, de acréscimo, como nos explica Barbosa (1990), exigindo, assim, um olhar livre e ao mesmo tempo crítico.

A noção de intervalo advinda das reflexões de Barbosa (1990) baseia-se na ideia de que, na leitura do texto literário, o leitor procura compreender as relações entre os significados linguísticos, sejam estes históricos, sociais, psicológicos etc., e o "modo" de sua realização textual; e tende, o leitor, a construir pares: literatura/história, literatura/ sociedade, literatura/psicologia etc. Barbosa (1990) propõe que se busque apreender essa relação por meio do próprio movimento interno de configuração do signo literário, "operando-se a aglutinação dos significados pela intensidade dos significantes textuais, fazendo desaparecer, nos limites, a prevalência isolada dos significados, sem 
que se esvaia a sua existência concreta" (BARBOSA, 1990, p. 11). Logo, o autor chama de leitura do intervalo esta leitura entre os dados da realidade e suas representações, e salienta, também, que o intervalo não é um "vazio", mas sim, aquele espaço/tempo em que a literatura se afirma como literatura, indo, assim, sempre mais além do que literatura. A ideia é, pois, a apreensão dos significados pela via da "tradução literária".

De acordo com Barbosa (1990), então, aquilo que é mais do que literatura na leitura do objeto literário conjuga-se a uma "organização específica de significantes", ou seja, singular, que os significados extraídos da leitura (psicologia, história, sociedade etc.) são definidos por esta organização.

Desse modo, ao lermos a obra como sendo mais do que literatura, lemos o sentido produzido pela própria composição e não somente a pressuposição de significados independentes, o que neste artigo foi discutido por meio das escolhas morfossintáticas, fonéticas e, portanto, fonológicas, bem como por meio da combinação destes elementos no eixo sintagmático. Este comportamento da palavra, aliás, ressalta 0 embate entre a contenção e a liberação do som articulado.

PUNCTUATION AS A STYLISTIC RESOURCE IN THE SHORT-SHORT STORY "FOSSO DO SOM", BY Jõ̃o GILBERTO NOLL

\section{ABSTRACT:}

The main purposes of this article are to analyze and to describe the procedure through which Portuguese linguistic rules about punctuation may be disarranged in João Gilberto Noll's short-short story called "Fosso do som", that is part of his work Mínimos, Múltiplos, Comuns. We consider that this process works as a stylistic resource which contributes to structuring the narrative's poetic plot. Moreover, having in mind the misuse of some grammatical rules, we will analyze the text's syntactic structure which has resulted from verb-phrase ellipsis and also from prose structure itself, according to the Russian formalism.

KEYwORDS: short-short story, plot, punctuation, ellipsis, poetic function. 
LA PUNTUACIÓN COMO RECURSO DE ESTILO EN EL MINICUENTO “FOSSO DO SOM” DE Jõ̃o GilberTo Noll

\section{Resumen:}

Este artículo propone analizar y describir de qué forma la puntuación normativa de la Lengua Portuguesa se desconfigura en el microrrelato Fosso do som de João Gilberto Noll, en su obra "Mínimos, Múltiplos, Comuns" y, por ello, funciona como un recurso de estilo que contribuye para la organización de la trama poética de la narrativa. Además, teniendo en cuenta el desvío de esa regla gramatical en cuestión, será observada la estructura sintáctica del texto que resulta en elipsis en las frases y en la propia estructura del género prosa de acuerdo con los formalistas rusos.

PALABRAS-ClaVe: mini-cuento, trama, puntuación, elipsis, función poética.

\section{REFERÊNCIAS}

AULETE, C. Minidicionário contemporâneo da língua portuguesa. Rio de Janeiro: Lexikon, 2011.

BACHELARD, G. A poética do espaço. Tradução Antônio da Costa Leal e Lídia do Valle Santos Leal. São Paulo: Martins Fontes, 1989.

BARBOSA, J. A. A leitura do intervalo: ensaios de crítica. São Paulo: Iluminuras/ Secretária de Estado da Cultura, 1990.

BARTHES, R. Crítica e verdade. Tradução Leyla Perrone-Moisés. São Paulo: Perspectiva, 1970.

BORGES FILHO, O. Espaço e literatura: introdução à topoanálise. Franca, SP: Ribeirão Gráfica e Editora, 2007.

CORONADO, G. de la C. Teoria do conto. Estudos Anglo-Hispânicos. São José do Rio Preto, Faculdade de Filosofia, Ciências e Letras de SJRP - SP, n. 2-3, p. 15-45, 1969-1970.

CUNHA, C.; CINTRA, L. Nova gramática do português contemporâneo. Rio de Janeiro: Nova Fronteira, 2001.

GENETTE, G. Discurso da narrativa. Tradução Fernando Cabral Martins. Lisboa: Vega, 197-.

GONÇALVES, A. J. Noções de estilística. s.d. 
JAKOBSON, R. Linguística e comunicação. Tradução Izidoro Blikstein. São Paulo: Cultrix, 1969.

JUNG, C. G. (1945). Da essência dos sonhos. Tradução M. R. Rocha. In: . A dinâmica do inconsciente. Petrópolis: Vozes, 1984, p. 287-306.

LINS, O. Lima Barreto e o espaço romanesco. São Paulo: Ática, 1976.

MONTEIRO, C. A. F. O mapa e a trama - ensaios sobre o conteúdo geográfico em criações romanescas. Florianópolis: Editora da UFSC, 2002.

NOLL, J. G. Mínimos, múltiplos, comuns. São Paulo: Francis, 2003.

PIGLIA, R. Formas breves. São Paulo: Cia. Das Letras, 2004.

SILVA, T. C. Fonética e fonologia do português. São Paulo: Contexto, 2003.

TODOROV, T. Poética. Tradução Carlos da Veiga Ferreira. Lisboa: Teorema, 1986.

TOMACHEVSKI, B. Temática - a escolha do tema. In: EIKHENBAUM, B. et al. Teoria da literatura: formalistas russos. 2 ed. Trad. Ana Maria de Ribeiro, et al. Porto Alegre: Globo, 1976.

VALÉRY, P. Variedades. João Alexandre Barbosa (Org.). São Paulo: Iluminuras, 1999.

Submetido em 28 de fevereiro de 2016.

Aceito em 20 de maio de 2016.

Publicado em 29 de setembro de 2016

98 Passos, L. A pontuação como ReCURso de estilo no miniconto “Fosso do som”, ,... 